\section{A Colour Atlas of Head and Neck Anatomy}

By R. M. H. McMinn, R. T. Hutchings and B. M. LogaN Pp. 240, illustrated. Wolfe Medical Publications, London, 1981. $£ 18.00$.

This is a spectacular book in every sense of the word. The authors have taken Vesalius and his Victorian successors and re-created with tremendous care a photographic text book of real anatomy. I am sure the selective formalized drawings of Gray, Jameson and Grant are valuable to the undergraduate student but for clinical practice one must return to the three-dimensional complexity of the body itself.

The contents are divisible into osteology, soft tissue dissections, the brain and spinal cord and radiographs.

With the illustrations on the left page and the text on the right, the maximum size for display has been achieved with a simple means of anatomical self-assessment for students of all ages. The authors make no claims to provide a detailed text but there are useful captions on many pages to supplement the identification keys.

Several illustrations look a little flat, e.g. the base of skull and the infra-temporal region, but this does not detract from the overall wealth of detail.

The weakest section contains the radiographs and angiograms; this needs more detailed radiographs, including an angiogram of the external carotid branches. This section might also benefit from some subtraction films and CT scans but then the authors could legitimately say, where do we stop?

In summary, this is a beautifully prepared, valuable text book for students and surgeons concerned with the anatomy of the head and neck. It is conveniently sized and surely well worth the present price of $£ 18$.

\section{HARRIS \\ Institute of Dental Surgery, London.}

\section{A Colour Atlas of Rheumatoid Hand Surgery}

By K. M. BaCkhouse, S. H. HARRISON and R. T. HutchINGS. Pp. 216, illustrated. Wolfe Medical Publications, London, 1981. £35.00.

This book is pleasantly written, excellently illustrated and enjoyable to read. The early chapters concerning the principles of surgery to patients suffering from rheumatoid arthritis and the examination of the hand in such patients are full of common sense and advice suitable for trainee surgeons. Details of surgical procedures, illustrated beautifully with colour photographs (sometimes excessively), seem intended for more senior surgeons, possibly at the stage when rheumatoid surgery is becoming a special interest. The technical aspects are dealt with clearly, but perhaps a little more space could have been given to postoperative care following individual surgical procedures. It is this deficiency which diminishes the book's value as a text book of surgical procedures.

Nevertheless, senior registrars or consultants interested in the surgery of rheumatoid arthritis should certainly wish to own this book for reference purposes and for the pleasure of looking through its pages.

\section{Paton \\ Whittington Hospital, London.}

\section{Controversies in Clinical Care}

Edited by Victor M. Rosenoer and Marcus RothsCHILD. Pp. 234, illustrated. MTP Press, Lancaster, 1981. £17.75.

I enjoyed this book and found it balanced, readable and worthwhile. The Introduction and first two chapters led me to assume that I was going to read critical analyses of the main papers confirming or refuting the different approaches when orthodox clinical management is controversial. However, this applied only to the chapter on lithium maintenance therapy in manic depressive disorders. Nonetheless, all the other chapters were excellent reviews of some of the most common current controversies in clinical care. The eleven topics of the reviews are mainly of relevance to physicians; the only possible exception being a review of adjuvant therapy of breast cancer but even this topic reflects the involvement of physicians as oncologists in what has traditionally hitherto been considered a surgical disease. Among interesting and clinically relevant topics covered are alcoholism, acute and chronic hepatitis, gall-stone disease, hypertension, transient ischaemic attack and albumin therapy.

The book is pleasurably produced and printed. I found no textural, grammatical or factual errors. The chapter references contain the titles of the articles referred to (this usually implies considerable care in preparation and ensures that the references are truly relevant). I detected careful and consistent editing in that the chapter introductions were uniformly competent.

\section{J. T. DAviES \\ Raigmore Hospital, Inverness.}

\section{Davidson's Principles and Practice of Medicine}

Edited by John Macleod. Pp. xiii +943 , illustrated. Churchill Livingstone, Edinburgh, 1981. £11.50 (paperback), $f 16.00$ (hardback).

What can a reviewer say about a text book of medicine which is now in its 13 th edition and which has been translated into four languages? The first five chapters consider various general aspects of disease such as genetic and nutritional factors. The following chapters consider disease in a conventional systematic way and they also include psychiatry, tropical medicine and acute posioning. A final and new chapter on promotion of health and prevention of disease completes the book.

There can be very few topics from the very wide range chosen by Membership Examiners on which prospective candidates would not find at least a short note. Gram for gram, there can be few books which supply so much information in such a readable and digestible form. It can be highly recommended for both undergraduates and postgraduates.

$£ 11.50$ for the soft-backed edition puts it well within the scope of the most impoverished student.

\section{E. Sharland Whittington Hospital, London.}

\section{Multiple Choice Questions in Haematology with Answers and Explanatory Comments}

By G. D. Pegrum and T. R. Mitchell. Pp. 63. Edward Arnold, London, 1981. £1.95.

This is a little book which contains a surprisingly large amount of information. A few of the questions are somewhat confusing or too high powered for the intended market but surely this is a criticism familiar to all who have sat for multiple choice examinations.

The price is low enough to ensure that students will be able to buy and thumb through this volume in the days before their examinations knowing that, if they are successful, the 
book will not be of any value afterwards. Part I M.R.C.P. students would also do well to spend a few hours perusing the contents of this book.

N. PARKER
Whittington Hospital,
London.

\section{Pancreatic Cancer}

A Series of Workshops on the Biology of Human Cancer, Report No. 12. UICC Technical Report Series, vol. 57. Edited by Isidore CoHN JR and Paul R. Hastings. Pp. 142, illustrated. International Union against Cancer, Geneva, 1981. Sw. fr. 20.

This is the résumé of a workshop on pancreatic cancer sponsored by the International Union Against Cancer, bringing together a small group of international experts. The scene is set with a chapter on epidemiology, reflecting the increasing mortality in advanced countries, and the paucity of our understanding of the reasons for this epidemic. This is followed by a review of the pathology of non-endocrine tumours, based on a personal series of 645 patients. The authors emphasize the important prognostic differences between different cell types and sites of origin. The chapter on endocrine tumours is brief and authoritative but does not cover diagnostic aspects in detail.

Chapters on carcinogenesis, animal models, the biology of tumour cells, and the effects of diet on the exocrine pancreas give a broad over-view of present experimental research, without providing much hope for a sudden breakthrough in understanding. Likewise, the survey of pancreatic tumour markers might be depressing if the goals were not so tantalizing.

For the clinician, the chapter on prognosis and the results of treatment must be profoundly depressing-but leads reasonably into some guidelines for 'better co-ordinated, more productive and co-operative research effort on an international basis'.

This is a short and valuable source document for all those interested in the subject of pancreatic cancer. Individual contributions are well written and edited, and are accompanied by more than 400 references.

\section{P. B. Cotton The Middlesex Hospital, London.}

\section{Problems in Geriatric Medicine}

By Anthony Martin. Problems in Practice Series. Pp. 195, illustrated. MTP Press, Lancaster, 1981. £7.95.

There is now a significant range of texts on geriatric medicine, from books for undergraduates through to comprehensive tomes; this text book is one of a series designed to help general practitioners and is attractively produced. The vascular system is obviously of interest to the author and the relevant chapters are capably presented; the chapter on incontinence by Roger Briggs is also well done. The question of balance in such a wide ranging book, however, has clearly caused problems; there are nine pages on heart block and two on diabetes; Lenègre's syndrome gets a mention while the clinical features of depression get sixteen lines. There are contradictions in the text (between 4 and $6 \%$ of the population over the age of 65 years suffer from definite organic psychiatric disorders in one paragraph while the next. paragraph describes dementia affecting $10 \%$ of the ove $65 \mathrm{~s}$; nitrazepam as a hypnotic is to be avoided in one? chapter but may be used in another and 'incidence' is corre fused with 'prevalence'. There are some factual errors, suclf as in the biochemistry of calcium metabolism.

In the use of drugs a dose of $62.5 \mathrm{mg}$ of digoxin will not be suitable for all old patients, the dose of vitamin $D$ re commended as a starting dose for all patients in the treatment of osteomalacia $(1.25 \mathrm{mg})$ can be toxic and is 100 times mores than others would use, the long-acting sulphonylure chlorpropramide is avoided by many geriatricians while carbimazole still has a place in the control of thyrotoxicosis and few would rely on propranolol and radioiodine. Therø is an index but no references are given. The general praco titioner may well find one of the other text books on gerias tric medicine more reliable.

R. V. Boyd

University of Nottingham, Medical School.

\section{Scientific Foundations of Surgery}

Edited by JAMES KylE and JAMES D. HARDY. 3rd EdnPp. xiv +712 , illustrated. William Heinemann Medica $R$ Books, London, 1981. $£ 48.00$.

In 1967, Professor Charles Wells and James Kyle publishef an exciting experiment-a text book produced by surgeogs $\vec{r}$ physicians, pathologists and anatomists, which described of fundamental principles upon which clinical practice depents This was the first of the 'Scientific Foundations' series, wkenhas now spread to some fifteen specialities. In this thrth edition, Professor Wells has now retired as co-editor and has been replaced by Dr James Hardy, currently the Presiden 5 of the American College of Surgeons. The team of eighty four other contributors is drawn from the U.S.A. Canada South Africa, and Austrailia, as well as the United Kingdom? and includes many names of international authority.

After preliminary chapters on the cell, genetics and congenital abnormalities, there is a detailed section on immunology and transplantation. Following this, each of the majo systems is considered in turn. There are then sections on inflammation, wound healing, cancer, microbiology, sterilization and hospital infection. A particularly welcome chapter is on parasitology for surgeons which will be of interest to surgeons working in tropical countries and those who may be confronted by patients recently returned from overseas.

The text reads well, the illustrations and tables are copious and clear and the bibliography both up to date and informa tive.

This third edition maintains the high traditions of its predecessors and, like them, will prove valuable both to surgeons in training, who are studying for their Primary F.R.C.S., and to more senior men who require an up too date source-book on the scientific foundations of their speciality.

H. Ellis Westminster Medical School, London. .}

